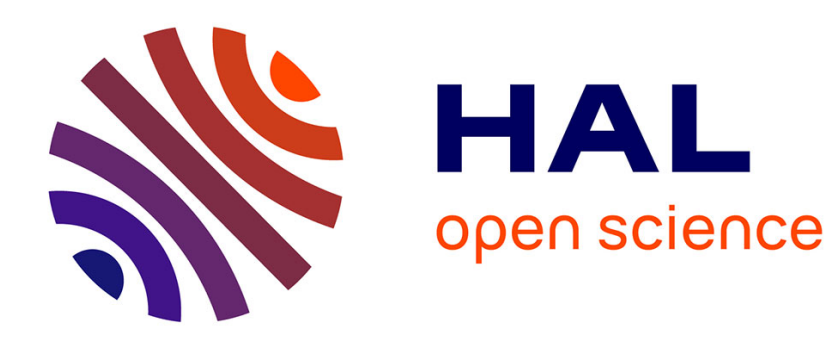

\title{
The applications of Mössbauer Spectroscopy in heterogeneous catalysis research
}

\author{
P. Bussière
}

\section{To cite this version:}

P. Bussière. The applications of Mössbauer Spectroscopy in heterogeneous catalysis research. Revue de Physique Appliquée, 1981, 16 (9), pp.477-490. 10.1051/rphysap:01981001609047700 . jpa-00244940

\section{HAL Id: jpa-00244940 https://hal.science/jpa-00244940}

Submitted on 1 Jan 1981

HAL is a multi-disciplinary open access archive for the deposit and dissemination of scientific research documents, whether they are published or not. The documents may come from teaching and research institutions in France or abroad, or from public or private research centers.
L'archive ouverte pluridisciplinaire HAL, est destinée au dépôt et à la diffusion de documents scientifiques de niveau recherche, publiés ou non, émanant des établissements d'enseignement et de recherche français ou étrangers, des laboratoires publics ou privés. 


\title{
The applications of Mössbauer Spectroscopy in heterogeneous catalysis research $(*)$
}

\author{
P. Bussière \\ Institut de recherches sur la catalyse du C.N.R.S., 2, avenue Albert-Einstein, 69626 Villeurbanne Cedex, France
}

(Reçu le 24 février 1981, révisé le 3 juin 1981, accepté le 5 juin 1981)

\begin{abstract}
Résumé. - La Spectroscopie Mössbauer est de plus en plus utilisée dans les recherches en catalyse hétérogène, où sont mis en jeu des solides dont la complexité et l'état de division gênent souvent la caractérisation par les méthodes plus habituelles. A l'aide de quelques exemples nous récapitulons les particularités qui affectent les paramètres RGN des catalyseurs, puis nous montrons comment la Spectroscopie Mössbauer permet d'identifier des phases actives en catalyse, et d'étudier les phénomènes d'adsorption et les mécanismes réactionnels. Nous mettons l'accent sur les questions qui restent à résoudre et les perspectives de la méthode.
\end{abstract}

\begin{abstract}
The importance of Mössbauer Spectroscopy in heterogeneous catalysis research is increasing, since more and more catalysts are complex finely dispersed solids, sufficient characterization cannot be achieved easily with more conventional methods. After summarizing the special features of Mössbauer Spectroscopy of solid catalysts, we show and discuss some examples of its use in identifying catalytically active phases, in studying adsorption phenomena, and reaction mechanisms. Questions that remain and perspectives given by Mössbauer spectroscopy in heterogeneous catalysis research are presented $\left(^{*}\right)$.
\end{abstract}

1. Introduction. - As discussed in the precedent articles [1-3], the mechanism of a catalytic reaction involves several steps and its determination is usually a rather difficult task. As several steps involve bonding of reactants or of intermediate reactive species to the solid catalyst, it is necessary to know very well the composition of the catalyst, the structure of its components, and their physico-chemical behaviour before attempting to solve a problem in heterogeneous catalysis. Unfortunately every solid state technique suffers some kind of limitation. Moreover even the most favourable cases need using several techniques, because of either the complexity of the catalyst or a high dispersion or a small content in the active phase or all these reasons together. The examples which have been developed in [1-3] clearly show what information is required : electronic state, structural neighbourhood, magnetism. Answers to these questions can be found in a Mössbauer (or NGR, Nuclear Gamma Resonance) spectrum, and such an approach to problems in heterogeneous catalysis began about fifteen years ago, in spite of the fact that a few chemical elements are available for NGR. The main reason is that the most suitable elements, iron and

$\left(^{*}\right)$ Conférence présentée à la réunıon 1980 du Groupe Français de Spectrométrie Mössbauer (75). tin, are some of the major components in many industrial or model catalysts. However in such investigations antimony, cobalt, europium, gold, iridium, platinum, ruthenium, tellurium were also involved. At present about 250 references are relevant to this subject [5] and review papers are available for a complete comprehensive bibliography to date [6-9]. Here we use a few examples to show the main contribution of Mössbauer spectroscopy to heterogeneous catalysis research, the questions that remain, and the perspectives that are gained, by examining successively :

- the peculiarities in the use of NGR in these investigations,

- the explanation of catalytic properties from the identification of catalyst components,

- the studies of chemisorption,

- the studies of catalysts during catalytic reactions.

2. Particularities in the use of NGR in heterogeneous catalysis research. - Some particularities arise chiefly from the fact that the catalytic solids are powders with mean particle sizes $\bar{d}$ in the range 1 to $100 \mathrm{~nm}$ and dispersions $D$ (number of surface atoms/ total number of atoms) from about 1 to about 0 res- 
pectively [1]. The Mössbauer parameters of the most dispersed catalysts may undergo deviations from the values known for large particles of the same species, as previously discussed to some extent $[8,10]$. We summarize here these features, taking into account some more recent results and pointing out the main questions for which an answer is yet needed. Some typical examples will be used, especially the very instructive work of Bartholomew and Boudart on Pt-Fe/C [11], illustrated in figure 1 , where all the hereafter discussed effects are found owing to the choice of a support chemically inert in the conditions of the experiments. Particularities in methodology and special physicochemical behaviours are also presented.

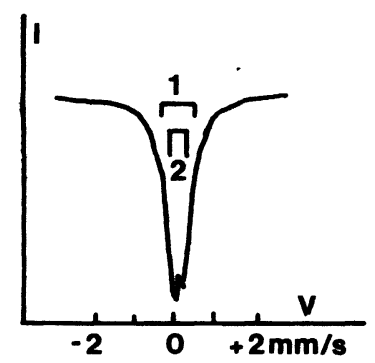

Fig. 1. - NGR spectrum of a finely dispersed Pt-Fe/C catalyst in hydrogen. After [11].

2.1 ISOMER SHIFT. - Since a dependence of the densities of electronic states on particle sizes is stated $[12,13]$, it may be asked wether this appears in the experimental values of $\delta$. A difficulty results from the chemical preparation of the finely dispersed catalysts, from which the last reagent $\mathrm{CH}_{2}$ or $\mathrm{CO}$ for instance in the case of metals) cannot be easily removed and has an electronic interaction with surface atoms (see section 4 later). The variation of the isomer shift due to this interaction would compete with the eventual effect of a small size of the particles.

When the latter is larger than ca 5-6 nm, the isomer shift with respect to that of large particles, - let us write $\delta^{\prime},-$ is generally null at room temperature and above. Even $4 \mathrm{~nm}$ particles of $\mathrm{SnO}_{2}$ give

$$
\delta^{\prime}=0.00 \pm 0.02 \mathrm{~mm} \cdot \mathrm{s}^{-1}
$$

at $295 \mathrm{~K}$ [14]. Low temperature measurements result in a less clear situation, for instance 4 and $6 \mathrm{~nm}$ particles of gold embedded in gelatin exhibit values of $\delta^{\prime}$ between +0.04 and $0.20 \mathrm{~mm} . \mathrm{s}^{-1}$ at $4 \mathrm{~K}$ without correlation with the size [15] and for $6 \mathrm{~nm}$ particles of iron supported on silica $\delta^{\prime}$ at $78 \mathrm{~K}$ is null for the bulk and $+0.16 \mathrm{~mm} \cdot \mathrm{s}^{-1}$ for the desorbed surface layers [16].

Therefore it seems to be more promising to examine the behaviour of smaller particles. The results obtained with very dispersed metallic iron catalysts are reported in table $\mathrm{I}$. In the most reliable cases of fine grains of alloys (1.5 to $3 \mathrm{~nm}$ ), Pt-Fe supported on graphite [11] or alumina [22] and Pd-Fe on alumina [22], $\delta^{\prime}=0.00 \pm 0.02 \mathrm{~mm} \cdot \mathrm{s}^{-1}$ for the bulk of the particles and often also for the surface layers covered or not by hydrogen.

Table I. - Isomer shift $\delta^{\prime}$ of small particles of iron metal in catalysts with respect to that of large grains, at room temperature.

\section{Catalyst}

Conditions for the NGR spectra

$\bar{d} \mathrm{~nm}$ of iron metal

$\delta^{\prime} \mathrm{mm} \cdot \mathrm{s}^{-1}$

Reference

$$
\begin{array}{ccc}
\mathrm{Fe} / \mathrm{MgO} & \mathrm{Fe} / \mathrm{MgO} & \mathrm{Fe} / \mathrm{Al}_{2} \mathrm{O}_{3} \\
\text { in } \mathrm{H}_{2} & \text { after reduction of } \mathrm{Fe}^{3+}
\end{array}
$$

$$
2-4
$$$$
+0.07
$$$$
17
$$

2-3

$-0.07$

18

$\mathrm{Fe} / \mathrm{MgO}$
in vacuum after de-
composition of
$\mathrm{Fe}_{3}(\mathrm{CO})_{12}$
1.5
+0.06
20

$$
\begin{aligned}
& \mathrm{Fe} / \mathrm{C} \\
& \text { after decomposi- } \\
& \text { tion of } \mathrm{Fe}(\mathrm{CO})_{5} \\
& \text { « raft-like " } \\
& \sim 1 \mathrm{~nm} \text { thick } \\
& +0.06,0.00 \\
& 21
\end{aligned}
$$

From the uncertainty that appears for the results showed in table I, and more surely after the values for the bulk of finely dispersed supported-alloys, we can conclude that $\delta^{\prime}$, if there is one, equals at the utmost the usual accuracy in the determination of the isomer shifts for such systems.

Nevertheless, it could be fruitful to ask a second question about the isomer shift of supported small particles : is there an electronic interaction with the support ? Such an interaction was evidenced elsewhere; for instance in a study of thin iron films in contact with a silver coating the latter induced for the
$2 \mathrm{~nm}$ of iron above it an overall value of $\delta^{\prime}$ of about $+0.03 \mathrm{~mm} \cdot \mathrm{s}^{-1}$ [23]. Some similar effect could exist for the solids mentioned in the last paragraph, especially $\mathrm{Fe} / \mathrm{Al}_{2} \mathrm{O}_{3}$ included in table $\mathrm{I}$ because these iron particles were obtained inside micropores of alumina. A more striking situation arised with iron clusters of 8-9 $\AA$ inside supercages of $Y$ and A zeolites, where $\delta^{\prime}$ values of +0.22 and $-0.19 \mathrm{~mm} . \mathrm{s}^{-1}$ respectively were measured [24]. The former, because it is associated with a quadruple splitting of $0.7 \mathrm{~mm} . \mathrm{s}^{-1}$, could be only that of oligomers in reference to studies of implanted iron [25], unless it is the result of unexpect- 
ed oxidation. The value of $\delta^{\prime}$ for the A-zeolite seems to be due to an electronic interaction with surroundings. Perhaps some other poorly understood system could be cleared up by taking into account such an effect. The behaviour of two sets of $\mathrm{Fe}-\mathrm{Ru} / \mathrm{SiO}_{2}$ catalysts using the same silica but preparing the bimetallic clusters by a different procedure $[45,46$ could be relevant to this statement : in situ measurements of IS provided in both cases a value similar to that of a ferric ion in spite of a strongly reducing treatment, but in the first study the physicochemical behaviour of $\mathrm{Fe}-\mathrm{Ru}$ clusters was evidenced.

2.2 QUADRUPOLE SPLITTING. - The structural discontinuity at a surface is known to induce a modification of the electronic field gradients in its neighbourhood, not only of the lattice components but also of the electronic contributions [12]. In actual fact enlarged quadrupole splittings are observed for any species when $D$ is large enough, either for materials involved in the preparation of catalysts or for the catalysts themselves. Figure 1 gives a good illustration of the situation where both surface and bulk atoms are characterized from such an effect, the former by the doublet 1 with $\mathrm{QS}=0.73$ and the second by the doublet 2 with $\mathrm{QS}=0.245 \mathrm{~mm} . \mathrm{s}^{-1}$ [11]. Moreover, the differences in vibrations for the surface atoms with respect to those in the bulk are expected to result in an asymmetry of the Lamb-Mössbauer factor (Karyagin-Goldanskii Effect, KGE) for small particles. Many spectra of Pt-Sn/ $/ \mathrm{Al}_{2} \mathrm{O}_{3}$ catalysts exhibit both increased $\mathrm{QS}$ and the occurrence of a rather large

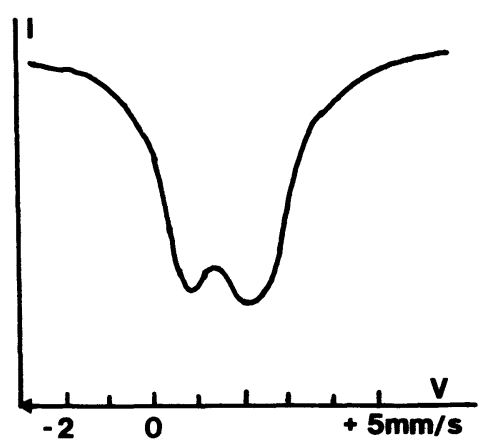

Fig. 2. - NGR spectrum of $\mathrm{Pt}-\mathrm{Sn} / \mathrm{Al}_{2} \mathrm{O}_{3}$ catalyst, $\mathrm{Pt} 0.95$ and Sn $0.55 \%$ by weight, in hydrogen. After [26].

Table II. - Tin Mössbauer parameters of a finely dispersed Pt-Sn $/ \mathrm{Al}_{2} \mathrm{O}_{3}$ catalyst, 0.95 and 0.55 w. $\%$ of $\mathrm{Pt}$ and $\mathrm{Sn}$ respectively.

Lines

$\left.\begin{array}{ccc}\begin{array}{c}\text { IS } \\ \left(\mathrm{mm} \cdot \mathrm{s}^{-1}\right)\end{array} & \begin{array}{c}\mathrm{W} \\ \left(\mathrm{mm} \cdot \mathrm{s}^{-1}\right)\end{array} & \begin{array}{c}\text { area of } \\ \text { spectrum } \\ (\%)\end{array} \\ 1.04 & - & \frac{1}{12.5} \\ 1.77 & 1.4 & 55 \\ 2.07 & 1.4 & 32.5\end{array}\right]$ PtSn

KGE for different species of tin [26], as seen in the case of figure 2 and correspondingly table II, obtained with finely dispersed metallic components $(D>0.5)$ : the two characterized alloys give quadrupole splittings which do not exist for these alloys in large particles, and the relative intensities are consistent with KGE at least for one of the doublets. Even iron NGR exhibits KGE in some instances, such as for supported $\mathrm{Pd}-\mathrm{Fe}$ alloys which give a ratio of the lines of 0.77 [22].

2.3 Magnetic InTERACTIONS. - The finely dispersed Pt-Fe alloys [11] show spectra such as that of figure 1 for compositions which for large grains would result in ordered magnetism and correspondingly six lines NGR pattern. This collapse of the hyperfine structure arises when the particle is small enough to induce the superparamagnetic behaviour, which is extensively discussed in another paper of the same series $[4,75]$. The internal field (and the Mössbauer sextet) reappears when temperature is sufficiently decreased such that the relaxation time associated with the flip of the spins, related to the particle size, becomes larger than the Larmor precession time for the nucleus. This effect provides a means to determine not only particle size but even their distribution, by recording spectra at different low temperatures (for instance particles of iron metal of $1.5 \mathrm{~nm}$ exhibit a blocking temperature of about $4 \mathrm{~K}$ ). Besides, the values of the hyperfine field can be a decisive help to achieve the characterization of the corresponding structure. Another kind of experiment that results in blocking the spins consists in supplying an external magnetic field. All these features lead to technical procedures, which we point out in 2.5.1 below, and allow applications whose examples can be found in almost all the following parts of this paper.

The question of the value of the hyperfine field $H_{\mathrm{s}}$ for surface layers in comparison to that $H$ in the bulk is another subject of interest, especially because it is a subject of controversy. A clear conclusion of many theoretical and experimental investigations is that there is an absence of a dead layer at a surface, and the main result of the extensive work performed on thin films is that $H_{s} / H$ depends chiefly on the nature of the interface [27]. But in the case of clean surfaces (under vacuum after desorption), $H_{s}$ was either calculated [12] and measured [28] as being equal to the bulk value or found theoretically [29] and experimentally [16] as being different from $H$. This point requires further investigation.

2.4 LAMB-MösSBaUER FACTOR. - As seen in 2.2 above, a feature of the hyperfine interactions for the nuclei near a surface is the departure of the relative intensities in a split spectrum from the usual values (KGE), due to an anisotropy of the Lamb-Mössbauer factor $f$.

Another particularity of this parameter for surface atoms is a drastic decrease of its value when the release 
of any adsorbate results in increased vibration amplitudes $x$, since $f=\exp -\left\langle x^{2}\right\rangle / \hat{\lambda}^{2}$, as stated many years ago $[30,31]$. The most striking experimental evidence for this phenomenon up to now is given by $\mathrm{Pt}-\mathrm{Fe} / \mathrm{C}$ catalysts (Fig. 1 [11]). By outgassing the hydrogen adsorbed during reduction, the doublet 1 fully disappears. Together with the large QS this behaviour enables one to ascrib this component of the spectrum to surface atoms. Moreover the ratio of the area of this doublet to the total area equals the dispersion measured by $\mathrm{H}_{2}-\mathrm{O}_{2}$ titration, which suggests a general method of determining this characteristics of a solid adsorbent. Unfortunately the most of the finely dispersed metal catalysts are prepared on reactive supports and the desorption of hydrogen creates a new system, inducing oxidation of an undetermined number of atomic layers of the oxidizable metal (see section 4).

Over the last few years, new attention has been focussed on the Lamb-Mössbauer factor of small particles, because extremely low values of $f$, down to $1 / 100$ th of the value $f_{0}$ for large particles or less, were reported in the case of non pressed fine powders. For instance, such a behaviour appears to some extent for the $\mathrm{Pt}-\mathrm{Fe} / \mathrm{C}$ alloys [11], which are reported as giving $f / f_{0} \sim 0.2$, and more drastically for $\mathrm{Ru} / \mathrm{SiO}_{2}$ catalysts (NGR of ${ }^{99} \mathrm{Ru}$ ) whose resonant absorption was not perceptible [32]. The publications dealing with this topic were reviewed recently in the introduction of a paper [14] which reconsidered the subject by using well characterized $\mathrm{SnO}_{2}$ powders of several mean sizes. As an illustration of this work, figure 3

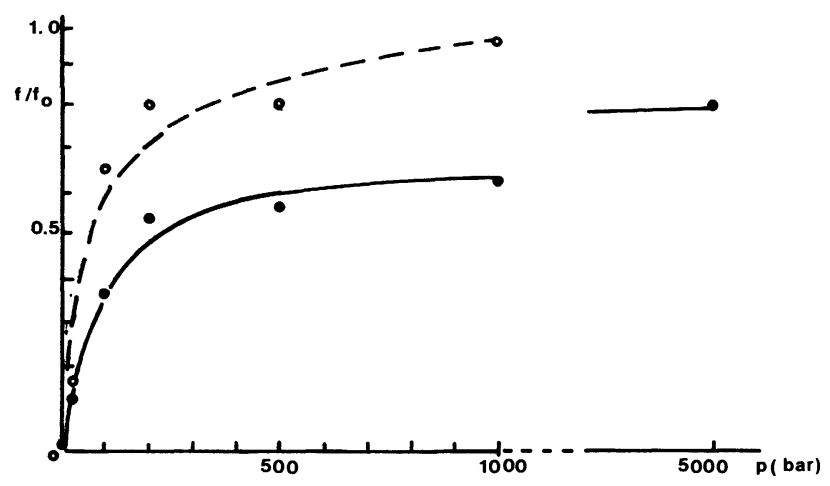

Fig. 3. - Dependence of recoilless fraction of $4.5 \mathrm{~nm} \mathrm{SnO}_{2}$ particles on compaction pressure, at $295 \mathrm{~K}(\odot)$ and $78 \mathrm{~K}(\mathrm{O})$.

shows the dependence of $f / f_{0}$ at 295 and $77 \mathrm{~K}$ on the compaction pressure $p$ used for preparating samples of the finest powder $(\bar{d}=4.5 \mathrm{~nm}, D \sim 0.2)$. The large effect of $p$, despite small changes in the related surface areas and the rather small effect of temperature rule out the explanation of low Lamb-Mössbauer factors by means of surface and bulk vibrations respectively. In addition, the values of IS, QS and linewidths $W$ for all the sizes exclude a determinant effect of recoil and brownian motion of isolated particles. The attenua- tion of $f$ could be ascribed to a more or less strong bonding of a particle to its neighbours, allowing the excitation of a vibration of the whole grain in the gamma-ray nuclear emission or absorption process. Therefore the Lamb-Mössbauer factor must be defined as the probability of no phonon and no grain vibrátion excitation, and written as the product of the two corresponding probabilities, the first being the usual Lamb-Mössbauer factor, written here as $f_{0}$, and the second could be designated by $f_{\text {part }}$ and calculated according to a suitable formalism.

Two approaches to this problem were published, both using the Einstein one frequency model of vibration of the particle as a whole. The first approach [33] considers the force constant $\xi$ of the movement and derives, in the high temperature approximation (at $300 \mathrm{~K}$ for instance), the following formula, where $E_{0}$ is the energy of the Mössbauer transition :

$$
f_{\text {part }}=\exp -\frac{E_{0}^{2}}{\hbar^{2} c^{2}} \frac{k T}{\xi} .
$$

The second approach [34] uses a treatment founded upon the frequency modulation of the $\gamma$ ray by the vibration of the particle and leads to a simple formula when $f_{\text {part }}$ is sufficiently large :

$$
\begin{aligned}
f_{\text {part }}=1-\varepsilon(\varepsilon \ll 1)=\exp - & \frac{h}{2 M \Omega \hbar^{2}} \times \\
& \times\left(\frac{2}{\exp (\hbar \Omega / k T)}+1\right)
\end{aligned}
$$

where $M$ is the mass of the particle and $\Omega$ its mean vibration frequency, $\lambda$ is the wavelength of the $\gamma$ ray.

Indeed the validity of these relationships is not easy to check, but they suggest the possibility of a variation of $f$ in the same way as the number and area of contacts of the particle with each others, which appears clearly in the experiments of compaction illustrated above.

The diminution of $f$ with particle size for weakly bound fine grains can be of a great importance in the studies of catalysts, where in such a case active components, especially those forming a small part of the solid, could escape the investigations more easily (cf. the already mentioned $\mathrm{Ru} / \mathrm{SiO}_{2}$ ), or when a quantitative study of the growth or decrease of a phase is wanted. In the latter case however the effect is not as troublesome as could be feared, inasmach as the ultimate traces are firmly embedded in another structure (see section 5).

2.5 Methodology. - 2.5.1 Samples and cells. The foregoing remarks about the Lamb-Mössbauer factor result generally in the requirement of pressing the powders up to at least $1 \mathrm{kbar} . \mathrm{cm}^{-2}$ (and in this manner the samples can be put in an horizontal beam). The diffusion of the gases into the pellet does not introduce a severe limitation to the study of an 
evolution of the catalyst during the reaction, because it is necessary to record a full spectrum, often complex, for each point and the accumulation needs at least thirty minutes under the best conditions (see the examples of section 5).

In order to investigate the state of a catalyst after reduction, adsorption, desorption or catalytic reaction, however large its dispersion, removing it from the conditions of such a treatment must be avoided. Even transference and packaging in a chemically inert atmosphere are often disappointing procedures. Each important NGR laboratory uses furnaces ready or easily modified so as to take a spectrum during the treatment of the sample in a flow of different gases or in vacuum, and as small as to stay in the air-gap of a magnet. More advantageous and less common are cells which enable one to obtain sample temperatures as well high as low. Mørup and coworkers [35] described a device in which the temperature of the pellet can be either raised to $700 \mathrm{~K}$ (or more by replacing Pyrex glass with silica in an element) or lowered to $78 \mathrm{~K}$ inside a magnetic coil. But the study of very small particles by means of magnetic relaxation (see 2.3 above) requires getting liquid helium temperature and the corresponding technical problem remains a challenge. An alternative lies in treating the catalyst in a removable reactor which can be put on the spectrometer.

2.5.2 Absorption Mössbauer spectroscopy. - Only the transmission method has been used up to now although it gives information about surface and bulk atoms as well and surface only is directly involved in adsorption and catalysis. The reason is not only the sake of technical easiness but also an interest for bulk states and the possibility of comparing them to surface atoms when the latter contribute clear components to the spectra because of a large dispersion. This appears throughout the examples described herein.

Nevertheless, one could wonder why conversion electron Mössbauer spectroscopy (CEMS) did not bring more enthusiasm to people working in catalysis, since it is said to concern mainly the surface layers. But more precisely, the range of the conversion electron from the usual Mössbauer transition of ${ }^{57} \mathrm{Fe}$ generally equals a fraction of a micrometer, and after the selection of the less attenuated electrons the thickness concerned is yet some tens of nanometers, i.e. about one hundred atomic layers. In the case of powders, often the grain size is smaller, so that the result would surely not be better than that of a gamma transmission experiment. The study of single crystals are more promising, on condition that it is possible to build the first atomic layers with isotopically pure ${ }^{57} \mathrm{Fe}$. In any case the difficulties of the detection and selection of the less attenuated conversion electrons would add the requirement of vacuum or a well defined atmosphere in the sample chamber.

2.5.3 Emission Mössbauer spectroscopy. - It is possible almost to double the number of chemical elements available for NGR investigations by using the studied atoms as Mössbauer sources. For instance, in studying a cobalt catalyst containing ${ }^{57} \mathrm{Co}$ by means of Mössbauer spectroscopy of ${ }^{57} \mathrm{Fe}$. The relevance of this method depends on (I) how the physicochemical behaviour of iron can be interpreted in terms of that of cobalt, (II) how troublesome the after effects are (physicochemical effects of the nuclear decay). In particular, it is necessary to refer to emission spectra of all the species involved in the investigation. Such a work is illustrated in section 5 .

2.5.4 Fe as a probe. - Another means to extend the field of applications of NGR in catalysts studies could be to introduce traces of isotopically pure ${ }^{57} \mathrm{Fe}$ into these solids during the preparation, then the Mössbauer spectroscopy of the probe nuclei could give some information about its surroundings. In fact this method suffers the same limitation as the previous method due to the physicochemical behaviour of iron. Also, the amount of the probe element should to be small enough to avoid any impurity effect. This can be achieved for the best by using carrier-free tracers. Examples are presented in sections 3 and 4.

\subsection{UNUSUAL PHYSICOCHEMICAL BEHAVIOURS. - It} must be briefly recalled that highly dispersed solids often react in a different manner than large particles, and that interactions can arise between some phases and their support. Thus $\gamma$-FeOOH does not decompose at $500^{\circ} \mathrm{C}$ in presence of magnesia, supported fine particles of iron metal are more or less oxidizable, platinum catalyses the reduction of $\mathrm{SnO}_{2}$ by hydrogen, etc...

3. The explanation of catalytic properties from the identification of catalysts components. - The first and most important step in catalysis studies is the unequivoqual characterization of the active solids. Even the knowledge of the intermediates in their preparation can provide information which result in improved preparation procedures and lead to a better understanding of the properties of the finished catalyst. Our topic is restricted to some typical examples dealing with finished catalysts and showing the efficiency of Mössbauer spectroscopy in rather complicate situations.

3.1 Bimetallic Catalysts. - In the search for improved activity and selectivity of metallic catalysts, the idea arose to use alloys or solid solutions of two (or more) metals, hoping to have a synergy effect which could be understood from the modification of the electronic properties of the components. Effectively new industrial and model catalysts of this type then appeared. Due to the requirements of a stable high alloy dispersion and the catalytic role of a support, the overall concentration of the metallic part of such solids is commonly on the order of $1 \%$ by weight with particle sizes on the order of nanometers. Accordingly, 
to determine whether one has an alloy rather than metal segregation is a difficult task. Often Mössbauer spectroscopy can solve this problem, and even give further useful informations.

3.1.1 Pt-Sn $/ \mathrm{Al}_{2} \mathrm{O}_{3}$. $-\mathrm{Pt}-\mathrm{Sn} / \mathrm{Al}_{2} \mathrm{O}_{3}$ catalysts with several metal composition were studied using NGR of Tin [36]. The preparation, according to an industrial procedure [37], involved the following steps : impregnation of alumina with an enriched ${ }^{119} \mathrm{SnCl}_{2}$ solu- tion, calcination, impregnation with $\mathrm{H}_{2} \mathrm{PtCl}_{6}$ solution, reduction by hydrogen. Due to such a procedure the knowledge of the Mössbauer parameters of a lot of tin species is necessary for achieving a good characterization of the finished solids : alloys at any composition, oxides, chlorides (oxygenated and hydrated as well) $[38,39]$. Taking into account the various aspects reported in section 2 for fine particles, it was possible to obtain the compositions given in table III (see in 2.2 the detailed example of catalyst $n^{\circ} 2$ ).

Table III. - Mössbauer parameters and composition of reduced $\mathrm{Pt}-\mathrm{Sn} / \mathrm{Al}_{2} \mathrm{O}_{3}$ catalysts.

\begin{tabular}{|c|c|c|c|c|c|c|}
\hline \multirow{2}{*}{$\begin{array}{l}\text { Catalysts } \\
\text { no }^{\mathbf{0}}\end{array}$} & \multicolumn{2}{|c|}{$\begin{array}{l}\text { Composition } \\
\text { (w. \%) }\end{array}$} & \multicolumn{2}{|c|}{$\begin{array}{l}\text { Mössbauer parameters } \\
\left(\mathrm{mm} \cdot \mathrm{s}^{-1}\right)\end{array}$} & \multirow{2}{*}{\multicolumn{2}{|c|}{$\begin{array}{c}\text { Main Sn species, area of spectrum } \\
(\%)\end{array}$}} \\
\hline & $\mathbf{P t}$ & Sn & IS & QS & & \\
\hline - & & & & & 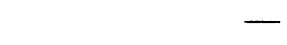 & \\
\hline 1 & 0.47 & 0.47 & $\begin{array}{l}0.58 \\
2.34 \\
1.95\end{array}$ & $\overline{4.2}$ & $\begin{array}{l}\mathrm{H}_{2} \mathrm{SnCl}_{6} \\
\mathrm{PtSn}_{4} \\
\mathrm{PtSn}\end{array}$ & $\begin{array}{l}30 \\
60 \\
10\end{array}$ \\
\hline $2 a$ & 095 & 095 & $\begin{array}{l}1.40 \\
1.92\end{array}$ & $\begin{array}{l}0.75 \\
0.3\end{array}$ & $\begin{array}{l}\text { Pt }: \text { Sn } 85: 15 \\
\text { PtSn }\end{array}$ & $\begin{array}{l}\sim 30 \\
\sim 70\end{array}$ \\
\hline $2 b$ & 0.93 & 0.95 & $\begin{array}{l}1.97 \\
1.88 \\
2.82\end{array}$ & $\begin{array}{l}4.25 \\
0.70 \\
2.60\end{array}$ & $\begin{array}{l}\text { PtSn } \\
\text { PtSn } \\
\text { SnO or } \mathrm{Sn}(\mathrm{OH})_{2}\end{array}$ & $\begin{array}{l}20 \\
40 \\
40\end{array}$ \\
\hline 3 & 0.50 & 0.20 & $\begin{array}{l}0.32 \\
2.30\end{array}$ & - & $\begin{array}{l}\mathrm{SnCl}_{4}, n \mathrm{H}_{2} \mathrm{O} \\
\mathrm{PtSn}_{4}\end{array}$ & $\begin{array}{l}65 \\
35\end{array}$ \\
\hline
\end{tabular}

Three main results appear to be important, insofar these compositions do not suffer any significant change under the conditions of the catalytic reaction. Firstly Pt-Sn alloys are present in all these solids, whose lowered activity in hydrogenation can now be attributed to the electronic poisoning of platinum inhibiting hydrogen chemisorption. The same reason explains the increased stability of such catalysts from a decrease of cracking. The second important result is the occurrence of ionic species, $\mathrm{Sn}^{2+}$ and $\mathrm{Sn}^{4+}$, depending on platinum and tin contents. These ions can react with strong acidic sites of alumina and the related activity in cyclization and isomerization proceeds by using the weaker acidity of the support. The third main result appears from the comparison of the overall concentration of platinum and tin with the compositions determined from Mössbauer spectra : for catalysts no 1 and $n^{\circ} 3$ a large part of the platinum is not included in the lines attributed to alloys. That a small part of tin contributes a dilute solid solution in platinum or that some amount of tin is alloyed to platinum inside very small particles with a low Lamb-Mössbauer factor cannot be excluded. It is also possible that tin ions induce some electronic change in neighbouring platinum atoms, as recently stated from ESCA studies.

3.1.2 Some other cases. - The bimetallic catalysts that contain iron were more extensively considered : $\mathrm{Fe}-\mathrm{Pt} / \mathrm{C}$ [11], $\mathrm{Fe}-\mathrm{Pt} / \mathrm{Al}_{2} \mathrm{O}_{3}$ and $\mathrm{SiO}_{2}$ [40, 41], $\mathrm{Fe}-\mathrm{Pd} /$ $\mathrm{Al}_{2} \mathrm{O}_{3} \quad[40,42], \quad \mathrm{Fe}-\mathrm{Ni} / \mathrm{SiO}_{2} \quad[43,44], \quad \mathrm{Fe}-\mathrm{Ru} /$
$\mathrm{SiO}_{2}[45,46]$. When small particles of a few nanometers were obtained, the existence of true alloys could be evidenced not only from their Mössbauer parameters but also from the special redox properties of the alloyed iron at room temperature. In particular this physicochemical behaviour ensures the identification of alloyed $\mathrm{Fe}^{0}$ surface atoms which exhibit a large isomer shift in supported $\mathrm{Fe}-\mathrm{Ru}$ aggregates, probably due to some electronic interaction with silica (see the end of paragraph 2.1). Alloying results in two kinds of catalytic behaviour, as can be seen for instance in Fischer-Tropsch synthesis : (I) the selectivity is the same as with either iron or the second metal alone where the latter is $\mathrm{Ni}$ or Pt, (II) it varies progressively with ruthenium content in the case of $\mathrm{Ru}-\mathrm{Fe}$ catalysts.

Because of the difficulties of platinum and iridium Mössbauer spectroscopy the system $\mathrm{Pt}-\mathrm{Ir} / \mathrm{Al}_{2} \mathrm{O}_{3}$ $(1.75 \%$ by weight of platinum and iridium) was studied by means of NGR of ${ }^{57} \mathrm{Fe}$ introduced as a probe [47]. Some clear results were obtained in the cases where platinum and iridium formed isolated phases. But it seems that the spectra attributed to Pt-Ir clusters could be interpreted by the two isolated phases containing the probe as well ; only chemisorption properties provided conclusive information. A surer answer was obtained with such catalysts containing $10 \%$ by weight of the metallic part [48] by using ${ }^{193} \mathrm{Ir}$ NGR, which could be improved in order to study smaller metal contents successfully. 
3.2 Oxide Catalysts. - As briefly stated in the paragraph 2.6, the procedures used to prepare catalytically active solids often result in unexpected phases. Among the most recent and striking examples of such a situation is that of magnesium ferrite reported in [49] : a small amount of $\alpha-\mathrm{Fe}_{2} \mathrm{O}_{3}$ appears, as particles large enough to exhibit a sextet in Mössbauer spectra at room temperature. This phase accounts for the activity in butene deshydrogenation since it disappears in correlation with the deactivation of the catalyst.

The tin-antimony mixed oxide catalysts for selective oxidation of hydrocarbons can be characterized by using NGR of the two cations. Samples of various compositions were prepared by thermolysis of the mixed hydroxides at various temperatures [50]. Most of them exhibit Sb Mössbauer spectra looking like that of figure 4. The $\mathrm{Sb}^{3+}$ component has an isomer shift (referred to $\mathrm{CaSnO}_{2}$ source) of $-14.2 \mathrm{~mm} . \mathrm{s}^{-1}$, different from that of $\mathrm{Sb}_{2} \mathrm{O}_{3}$ and close to that of $\mathrm{Sb}_{2} \mathrm{O}_{4}$.

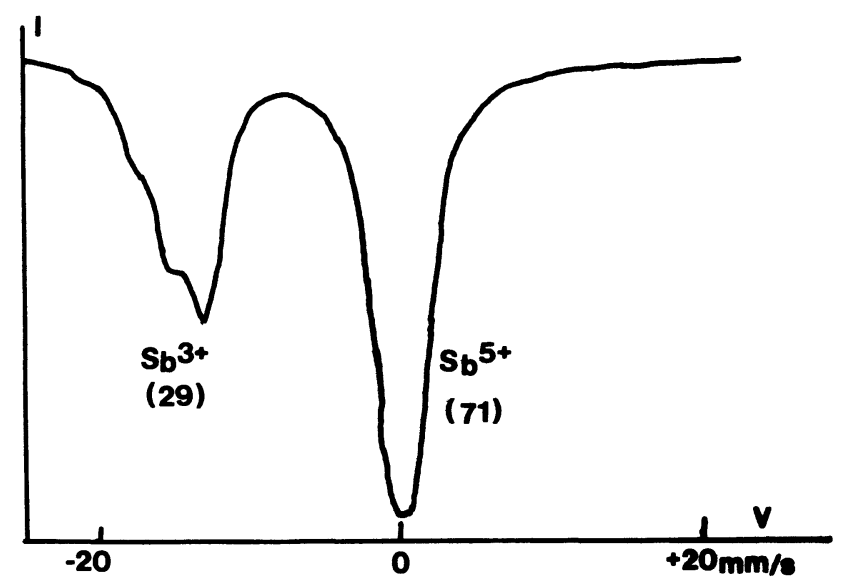

Fig. 4. - Sb NGR spectrum of a Sn-Sb-O catalyst. After [50].

Substracting the corresponding $\mathrm{Sb}^{5+}$ contribution to the overall $\mathrm{Sb}^{5+}$ pattern provides evidence for $\mathrm{Sb}^{5+}$ ions inserted within the $\mathrm{SnO}_{2}$ lattice, since their isomer shift is smaller than that of $\mathrm{Sb}_{2} \mathrm{O}_{5}$ by 0.5 to $1.2 \mathrm{~mm} . \mathrm{s}^{-1}$ and $\mathrm{Sb}_{2} \mathrm{O}_{5}$ cannot remain after the thermal treatment. NGR of tin indicates a modification of $\mathrm{SnO}_{2}$, from small variations of IS and QS. Therefore it is possible to estimate the concentration of the solid solution, by assuming that it involves all the $\mathrm{SnO}_{2}$ and that the antimony has there the same LambMössbauer factor as in $\mathrm{Sb}_{2} \mathrm{O}_{4}$. This results in the values given in table IV in dependence on the overall content $a$ of $\mathrm{Sb}$ and the temperature $T$ of thermal treatment. Clearly, the concentration of the solid solution decreases as $T$ increases.

These aspects of the behaviour of Sn-Sb-O catalysts introduced an improved approach to their reactive properties. Since $\mathrm{Sb}_{2} \mathrm{O}_{4}$ alone was known as a poor catalyst, the structure of the antimony oxide phase was reexamined by X-ray diffraction and was revealed to be structurally oriented [50], which could explain
Table IV. - Sb percentage of the solid solution $\mathrm{SnO}_{2}-\mathrm{Sb}(V)$ in mixed oxide catalysts in dependence on the overall $\mathrm{Sb}$ content a $(\%)$ and preparation temperature $T\left({ }^{\circ} \mathrm{C}\right)$.

$\begin{array}{cccc}T & 5 & a & \\ \overline{500} & \overline{5} & -\frac{10}{20} & - \\ 750 & 5 & 8.5 & 17.5 \\ 950 & & 7.5 & 13.5 \\ & 4 & & 8\end{array}$

an increased efficiency in selective oxidation. The solid solution of $\mathrm{Sb}^{5+}$ within $\mathrm{SnO}_{2}$ could play a role as well, since it appears reduced after use in butene oxidation [51], but neither its concentration as reported in table IV nor its Mössbauer parameters correlate with the selectivity for acrolein production. Therefore further investigation is r.eded.

4. Studies of chemisorption. - The most important chemical step in catalysis is chemisorption. Thus great progress towards the elucidation of a catalytic reaction is accomplished when the nature of the adsorptive sites and the bonding of reactants are determined. Mössbauer spectroscopy can resolve such problems by several means, even in rather complex situations, as enlighted by using some typical examples.

4.1 FerRous zeolrtes. - Let us recall that zeolites are aluminosilicates whose structures have the common property of having more or less opened channels and large cavities where molecules may enter and adsorb according to their size and reactivity. Exchange of zeolitic sodium with other cations is rather easy, as one or several sites are available for receiving the exchanged cations. The study of ferrous Y- [52] and A- [53] zeolites exemplify the ability of NGR to depict structural and chemical features of chemisorption, as partially and briefly explained below.

4.1.1 Water adsorption. - The ferrous ions introduced at an exchange rate of $60-70 \%$ within the very open structure of a Y-zeolite give rise, after full dehydration, to two NGR doublets, whose parameters are reported in table $V$. The first doublet exhibits an unusually small quadrupole splitting, independant of temperature, which is explained [54] in terms of a compensation of its electronic component

Table V. - Mössbauer parameters $\left(\mathrm{mm} . \mathrm{s}^{-1}\right)$ of ferrous zeolites before and after water chemisorption.

\begin{tabular}{|c|c|c|c|c|c|}
\hline \multirow[b]{2}{*}{ Zeolite } & \multicolumn{2}{|c|}{ Anhydrous } & \multicolumn{2}{|c|}{ Hydrated } & \multirow[b]{2}{*}{ Reference } \\
\hline & IS & QS & IS & QS & \\
\hline - & \multicolumn{2}{|r|}{ 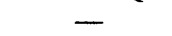 } & \multirow{3}{*}{\multicolumn{2}{|c|}{$\begin{array}{l}\text { disappeared } \\
\text { only decrease } \\
\text { in area }\end{array}$}} & - \\
\hline $\mathrm{Fe}$ (II) Y & 1.15 & 0.62 & & & $5 ?$ \\
\hline & 1.51 & 2.36 & & & 52 \\
\hline \multirow[t]{2}{*}{$\mathrm{Fe}$ (II) A } & 1.15 & 0.46 & 1.42 & 1.7 & \multirow{2}{*}{53} \\
\hline & & & 1.42 & 2.3 & \\
\hline
\end{tabular}


by the structural term in a planar environment of three zeolitic oxygen ions and another oxygen atom (for instance of an $\mathrm{OH}$ ). The corresponding place is the so-called site II, i.e. the centre of a sodalite window of a supercage. Hydration results in the disappearance of this doublet, meaning that iron was extracted into the intragranular fluid, which is consistent with the assigned site. The second type of ferrous ions has the Mössbauer parameters for a sixfold coordination to non equivalent oxygen atoms, as is possible in $\mathrm{Y}$-zeolites for the so-called sites $\mathrm{I}$ and $I^{\prime}$, i.e. inside an hexagonal prism of a sodalite cage. The effect of water adsorption on this spectrum component is essentially a decrease in intensity, meaning a loosening of the bonding to the zeolitic framework due to a coordination with water.

In $50 \%$ exchanged A-zeolite the ferrous ions are exchanged only in sites similar to site II above (see NGR parameters in table V). Hydration induces a progressive decrease of the corresponding doublet, up to its full disappearance when two water molecules per ferrous ion are adsorbed. Progressively two other doublets replace that of the anhydrous form; they characterize species such as (zeol. O) ${ }_{3}$ $\mathrm{Fe}^{2+}\left(\mathrm{H}_{2} \mathrm{O}\right)_{2}$ and (zeol. O) ${ }_{3} \mathrm{Fe}^{2+}\left(\mathrm{H}_{2} \mathrm{O}\right)\left(\mathrm{OH}^{-}\right)$.

4.1.2 Other adsorbates. - The two sites of ferrous ions in Y-zeolite, which imply two types of accessibility according to the size of reactant molecules, allow NGR to study such phenomena [52]. Ammonia interacts with the two sites, as in the case of water, but does not remove the ferrous ions of site II from the zeolite framework. The adsorption of larger molecules, (piperidin, t-butyl alcohol, $\mathrm{S}_{2} \mathrm{C}, \mathrm{EtOH}$ ) alters only slightly the corresponding wide doublet and their interaction with the other ferrous ions results in the vanishing of the narrow doublet, indicating a migration of these ions. In the chemisorption of ethylene, $\mathrm{CO}, \mathrm{NO}$, pyridin, only small modifications of all the components of the Mössbauer spectra occur, likely due to a weak bonding of these molecules to iron.

The latter situation could be better studied in A-zeolite [54] because of the existence of only one site. At room temperature after ethylene adsorption, the doublet parameters are IS $=1.15$ and $\mathrm{QS}=0.80 \mathrm{~mm} \cdot \mathrm{s}^{-1}$, which is a small modification of the values for anhydrous $\mathrm{Fe}$ (II) $\mathrm{A}$ in table $\mathrm{V}$. Also, the area decreases upon adsorption until one $\mathrm{C}_{2} \mathrm{H}_{4}$ molecule to two $\mathrm{Fe}^{2+}$ is retained. These features suggest weak bonding, resulting in a short residence time of ethylene in its adsorbed state, whose the spectrum could be therefore partly concealed. The relaxation of the ferrous ions between their two states, with and without adsorbate, could result in enlarged vibration amplitudes, giving a decrease in Lamb-Mössbauer factor. These assessments are supported by a series of NGR spectra at various low temperatures. A decomposition into two doublets becomes possible below $200 \mathrm{~K}$, showing that of iron in the complex with adsorbed ethylene (IS $=1.25$ and $\mathrm{QS}=1.1$ to $1.6 \mathrm{~mm} . \mathrm{s}^{-1}$ ). The estimation of the relaxation time of ferrous ions between the two corresponding sites, according to Wickman's formalism [55], provides a value of $23 \mathrm{~kJ} \cdot \mathrm{mol}^{-1}$ for the activation energy of this chemisorption.

\subsection{HYDROGEN CHEMISORPTION ON SUPPORTED IRON}

- The problem of the chemisorptive bond in hydrogen adsorption on metallic iron remains among the most attractive questions when dealing with the elementary steps in catalysis. So is it not surprising that efforts have been made to understand this phenomenon better by means of Mössbauer spectroscopy, in particular using the isomer shift to determine the nature of electronic structure changes when hydrogen is chemisorbed on or desorbed from this metal. The discussion about isomer shift of fine particles (see 2.1) introduced the difficulties encountered in these investigations. It follows that usually the comparison between adsorbed and desorbed states, without any other modification of the involved metal layers, could not be achieved. Moreover the dispersion of the values published for similar states of supported iron small particles (see table I) serves to blur the situation.

An especially severe limitation to such studies arises from the reactivity of supports, as illustrated in figure 5 in the case of $\mathrm{Fe} / \mathrm{MgO}$ catalysts [56. The spectrum of the reduced catalyst $(5 a)$ changed upon hydrogen desorption $(5 b)$; about $20 \%$ of the sextet vanished, one half giving rise to superparamagnetic metallic iron and the other half increasing $\mathrm{Fe}^{2+}$ pattern. The oxidation, indicated by the increase in $\mathrm{Fe}^{2+}$ lines, could be the origin of so small metal particles that they exhibit superparamagnetism. The desorption of another $\mathrm{Fe} / \mathrm{MgO}$ catalyst reduced at a lower temperature and rich in defects as indicated by broader NGR lines, induced even the total oxidation of the metal, as seen in spectrum $5 c$ where no trace of the initial sextet remains, whereas the components due to $\mathrm{Fe}^{2+}$ are increased by the corresponding area. Magnetization measurements corroborated this evidence for an oxidization. Infrared spectroscopic examination of $\mathrm{OH}$ groups of the support explained the phenomenon as a retention of hydrogen on the support as $\mathrm{OH}$ groups after reduction of the iron. An $\mathrm{Fe} / \mathrm{Al}_{2} \mathrm{O}_{3}$ catalyst appeared to behave similarly in Mössbauer spectroscopy [57]. NGR also established the occurrence of the same process with tin alloyed to platinum in $\mathrm{Pt}-\mathrm{Sn} / \mathrm{Al}_{2} \mathrm{O}_{3}$ [36]. Readsorption of hydrogen at the same temperature restored the reduced state. So NGR played an important role in ensuring the existence of a redox equilibrium involving the support for a supported pure or alloyed oxidizable metal Me [58], which can be written as a whole :

$$
\mathrm{Me}+n \mathrm{H}^{+} \rightleftharpoons \mathrm{Me}^{n+}+n / 2 \mathrm{H}_{2} \text {. }
$$

Since this effect was found to be small in the case of silica as a support [58], it is very interesting to 


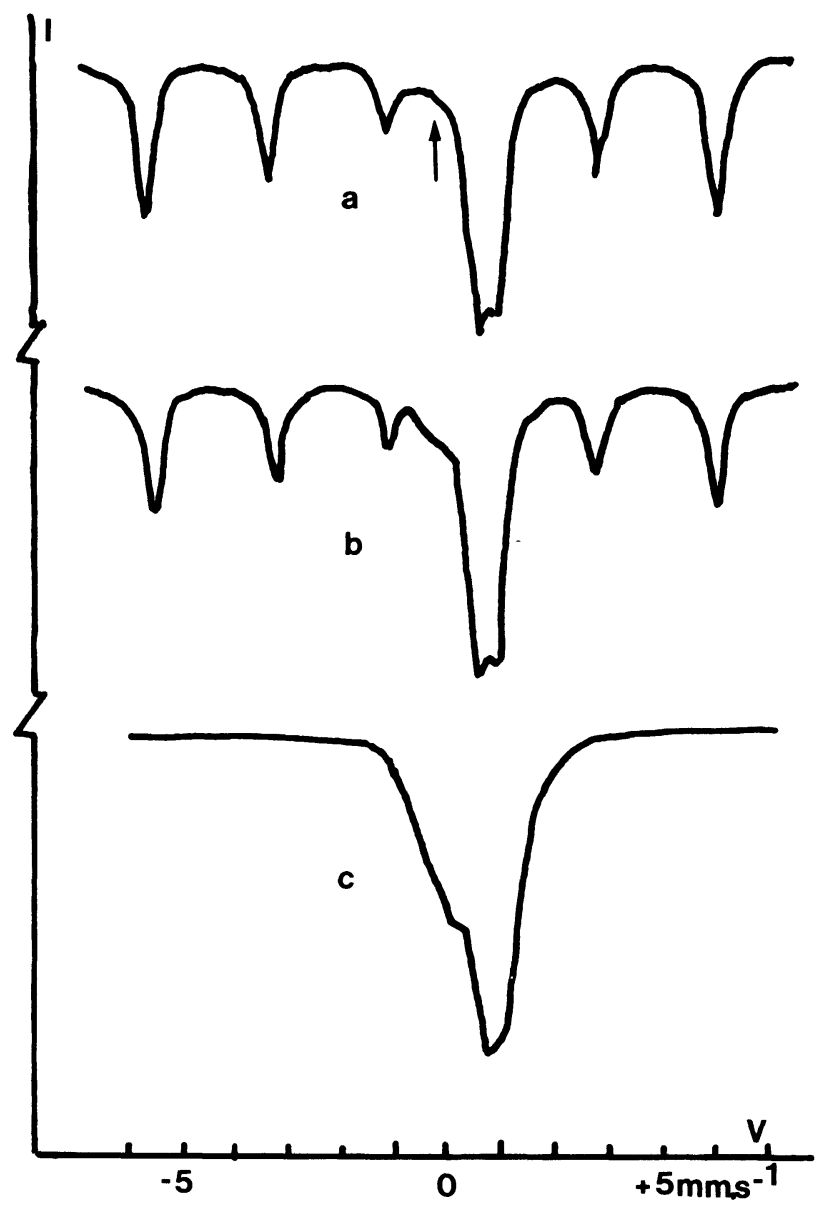

Fig. 5. - NGR spectra of $\mathrm{Fe} / \mathrm{MgO}$ catalysts : $(a)$ in hydrogen ; (b) the same after desorption; (c) a similar one after desorption. After [56].

consider the results of a very careful Mössbauer study of hydrogen adsorption on $\mathrm{Fe} / \mathrm{SiO}_{2}$ with a dispersion of $15-30 \%$ for the metal particles [59, 16]. The use of a special high-or-low temperature cell allowed all the treatments to be performed without moving the sample. In these conditions NǴR at $78 \mathrm{~K}$ in an external magnetic field of $12.4 \mathrm{kOe}$ gave the spectra shown in figure 6 [16], after outgassing in vacuum at $673 \mathrm{~K}(6 a)$ and after hydrogen chemisorption $(6 b)$. Each magnetic pattern is a sum of two components, one characteristic of bulk iron (nearly $38 \%$ of the spectrum area) and the other refered to as a surface component (6-9\% of the spectrum area). The following main Mössbauer parameters were computed for the latter : after desorption $\delta$ (with respect to $\mathrm{Fe}$ foil at $300 \mathrm{~K}$ ) $=0.26 \pm 0.04 \mathrm{~mm} \cdot \mathrm{s}^{-1}$ and $H$ (total at the nucleus) $367 \pm 3$ kOe, after hydrogen chemisorption $\delta=0.36 \pm 0.03$ and $H=373 \pm 3$. These changes are not very much larger than the errors, and the Lamb-Mössbauer factor for the surface component does not seem to vary significantly. Nevertheless, the excellent quality of the experiments inclines one to believe in the difference between the isomer shifts as well as between the hyperfine field of surface metallic iron in the adsorbed and desorbed states. More-

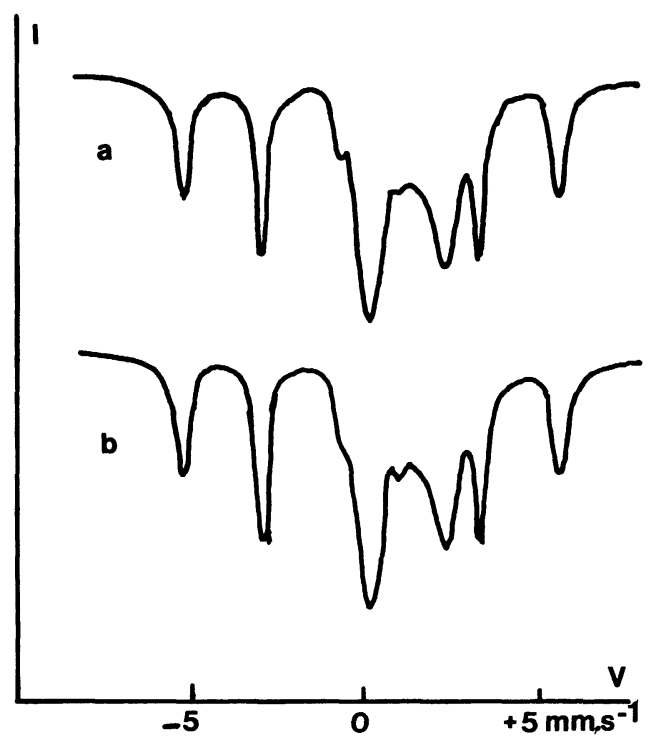

Fig. 6. - NGR spectra of finely dispersed iron of an $\mathrm{Fe} / \mathrm{SiO}_{2}$ catalyst : (a) after desorption; (b) after hydrogen chemisorption. After [16].

over a small increase in the anisotropy constant upon adsorption was also reported [59] and a similar behaviour appears in the case of CO (see 4.3). Therefore, the two proposed increases in $\delta\left(\simeq+0.1 \mathrm{~mm} \cdot \mathrm{s}^{-1}\right)$ and $H(\simeq+6 \mathrm{kOe})$ which occur upon hydrogen chemisorption can be accounted for by an increase in $3 \mathrm{~d}$ electron density.

4.3 CARBon MONOXIDE CHEMISORPTION ON IRON. Adsorption of $\mathrm{CO}$ at $200 \mathrm{~K}$ on the same $\mathrm{Fe} / \mathrm{SiO}_{2}$ catalyst exhibited similar features as that of hydrogen [59], and with the same accuracy increases in $\delta\left(\simeq+0.1 \mathrm{~mm} \cdot \mathrm{s}^{-1}\right)$ and in $H(\simeq+9 \mathrm{kOe})$ can be ascribed to chemisorption and are consistent with an increase in $3 \mathrm{~d}$ electron density. Adsorption besides gives rise to a quadrupole interaction $\left(\varepsilon=0.05 \mathrm{~mm} \cdot \mathrm{s}^{-1}\right)$ and seems to induce a small increase in the anisotropy constant [16].

4.4 HYDROGEN CHEMISORPTION ON NICKEL. Doping nickel with a small amount of ${ }^{57} \mathrm{Co}$, which does not affect its physicochemical properties, enabled the same researchers to investigate the behaviour of $\mathrm{Ni} / \mathrm{SiO}_{2}$ particles of about $4 \mathrm{~nm}$ in hydrogen chemisorption [60], using the values of the nickel hyperfine field at the ${ }^{57} \mathrm{Fe}$ nuclei. Of course the isomer shift of ${ }^{57} \mathrm{Fe}$ cannot be used since iron may be expected to behave otherwise than nickel, iron is created by electron capture decay and finally its very small quantity can result in particular states, for instances oxidation upon desorption (see 4.2 above). The increase in magnetic splitting upon increasing the external field was found qualitatively to be lowered by hydrogen chemisorption, indicating a reduction of the magnetic moment of the particles, as know from magnetization measurements and ascribed to a fill- 
ing of the nickel $3 \mathrm{~d}$ band by the electrons of adsorbed hydrogen. Using the volume of nickel particles, as determined from the magnetic splitting in several external fields, enabled to derive an anisotropy constant after desorption of $5 \pm 1 \times 10^{4}$ and after hydrogen chemisorption $3 \pm 1 \times 10^{4} \mathrm{~J}^{-\mathrm{m}^{-3}}$ either from the relaxation time or from the reduction of the observed hyperfine field at $4.2 \mathrm{~K}$ arising from collective magnetic excitations. This effect of chemisorption on the anisotropy constant of nickel is opposite to that reported, with similar accuracy, in the case of $\mathrm{Fe} / \mathrm{SiO}_{2}$. The question that remains is whether such results could be improved and whether this phenomenon can be described in terms of preferential orientation and surface anisotropy and reconstruction upon adsorption, since a wide range of anisotropy constant values results from various morphologies of the same solid particles [61].

5. Studies of catalysts during catalytic reactions. Although the composition of a catalyst before use and the knowledge of its chemisorption properties with respect to individual reactants give some ideas about a catalytic mechanism, such information is not sufficiently convincing since it is known that surface and even bulk compositions and structures often undergo some transformations during catalysis. It is necessary, therefore, to study a catalyst in the presence of reactants at the temperature of the reaction or at room temperature after quickly cooling without removing from the reactive mixture.

Indeed the former procedure is the surest one and allows and evolution study to be carried out over a long period without successive interruptions. The two first examples of this methodology appeared only some years ago [62], resulting in fundamental information : the sensitivity of ammonia synthesis to surface structure of an iron catalyst [63] and the increase in reduction of iron molybdates occurring from oxygen removal during oxidation of hydrocarbons [64].

Here we shall briefly detail the application of in situ Mössbauer spectroscopy in two fields of investi- gation, where it appeared to be an especially relevant approach to solving delicate problems.

\subsection{HydRODESUlPHURISATION Co-Mo catalysts.} - The enhancement of the efficiency of molybdenum as a catalyst in hydrodesulphurisation process by an addition of cobalt is not completely understood. Numerous attempts to describe cobalt in such solids in the presence of hydrogen and sulphided compounds resulted in different conclusions, i.e. cobalt is in either a metallic or a sulphided state. An extensive and careful NGR investigation was carried out, summarized in [65] and detailed in [66], chiefly on ${ }^{57} \mathrm{Co}$ labelled catalysts used as the sources and placed as pressed thin pellets inside a catalytic reactor permitting their Mössbauer spectra to be taken in the presence of the suitable atmospheres. The spectra were recorded mainly at room temperature, in the oxidized first state of the catalysts and after a treatment at $600 \mathrm{~K}$ in a flowing mixture of $2 \% \mathrm{H}_{2} \mathrm{~S}$ in hydrogen for 24 hours. Achieving the characterization of the cobalt species required studying the reference spectra of $\mathrm{CoMoO}_{4}, \mathrm{Co}_{9} \mathrm{~S}_{8}$ and $\mathrm{Co}: \mathrm{MoS}_{2}$.

An analysis of the main results for three high area supports can provide the characterizations presented in table VI, where cobalt and molybdenum contents are indicated in per cent by weight. Clearly, the nature of the support controls the formation of the oxide species (column after calcination) that act as precursors of the sulfided states. The interaction of the supported phases with a support appears weaker and weaker when going from alumina, wherein the major part of cobalt is inserted, to silica where the incorporated fraction is smaller, and finally to carbon where there is none. The results of sulfidation show a similar tendency, in particular giving a more or less large amount of a compound $M$. The authors identify $\mathrm{M}$ as their reference product $\mathrm{Co}: \mathrm{MoS}_{2}$ because not only the IS and QS are the same $\left(\mathrm{Co}_{9} \mathrm{~S}_{8}\right.$ has a smaller QS when in large particles, and here it could be finely dispersed) but also because of a dependence of QS on temperature (there is none for $\mathrm{Co}_{9} \mathrm{~S}_{8}$ ).

A more recent investigation [67], on such catalysts

Table VI. - Characterization of cobalt in HDS supported Co-Mo catalysts using emission Mössbauer spectroscopy, from an analysis of the results reported in [65] and [66]. $M$ : see text.

\section{Catalysts}

$\mathrm{Col} / \mathrm{Al}_{2} \mathrm{O}_{3}$
Col-Mo6/ $/ \mathrm{Al}_{2} \mathrm{O}_{3}$

$\mathrm{Col} / \mathrm{SiO}_{2}$

$\mathrm{Col}-\mathrm{Mo6} / \mathrm{SiO}_{2}$

Co1-Mo6/C
After calcination

Co in $\mathrm{Al}_{2} \mathrm{O}_{3}$

$\mathrm{Co}$ at least partly in surface layers of $\mathrm{Al}_{2} \mathrm{O}_{3}$

$\mathrm{Co}_{3} \mathrm{O}_{4}+\mathrm{Co}$ in $\mathrm{SiO}_{2}$

Co-Mo-O and/or

$\mathrm{CoMoO}_{4}$ poorly crystall.

$\mathrm{CoMoO}_{4}$ poorly crystall.
After sulfidation

following calcination

increase in $\mathrm{Fe}^{3+}$ component

super-imposition of low-spin $\mathrm{Fe}^{3+}: \mathbf{M}$

$\mathrm{Co}_{9} \mathrm{~S}_{8}$

$\mathrm{M}+\mathrm{Co}_{9} \mathrm{~S}_{8}$ (major part)

$\mathrm{M}+\mathrm{Co}_{9} \mathrm{~S}_{8}$ (little) 
prepared in a different manner and using non pressed powdered samples submitted to a somewhat more severe sulfidation treatment $\left(673 \mathrm{~K}, 10 \% \mathrm{H}_{2} \mathrm{~S}\right.$ in $\mathrm{H}_{2}$ ), found only $\mathrm{Co}_{9} \mathrm{~S}_{8}$ with $\mathrm{Co}-\mathrm{Mo} / \mathrm{Al}_{2} \mathrm{O}_{3}$ and Co-Mo/C (graphite, low and high surface area). At room temperature sulfided $\mathrm{Co}-\mathrm{Mo} / \mathrm{C}$ (carbon of very high surface area) gave an NGR spectrum similar to that of $M$, but it was found that not only $\mathrm{Co}: \mathrm{MoS}_{2}$ but also cobalt sulfoxides lead to this doublet.

However, this research provides very meaningful information : the role of the support in building active species, the absence of a rather large amount of metallic cobalt and the full sulfidation of this element in the fraction available for the catalytic reactions. Indeed the sensitivity for the detection of metallic cobalt strongly depends on dispersion, which is not well known. The relevance of the foregoing conclusions to HDS catalysis remains to be corroborated by catalytic activity measurements. So, much work is necessary since other physical methods of studying solid catalysts did not appear to be significantly more successful with this system but can give more conclusive data through an association with Mössbauer spectroscopy, chiefly by performing the latter during HDS reactions.

5.2 FISCHER-TROPSCH SYNTHESIS. - In spite of thirty years of investigation several important questions remain unresolved about the mechanism of the synthesis of hydrocarbons from carbon monoxide and hydrogen on iron catalysts. In the presence of the two reactants iron undergoes chemical transformations, mainly carburization, so that the first problem is to characterize the active sites. On the other hand the selectivities for hydrocarbons with a different number of carbon atoms and for olefins has not received any definitive explanation. A particularly interesting case is that of catalysts whose catalytic properties are changed either by the addition of another element to iron or by changing or modifying the support. Obviously an understanding of the corresponding behaviours requires a good knowledge of the active solids, necessarily in the conditions of the catalytic reaction which is known to transform them. Mössbauer spectroscopy is quite convenient for such a work, as revealed in several recent publications dealing with iron based catalysts.

Figure 7. illustrates the efficiency of this method in the study of an $\mathrm{Fe} / \mathrm{Al}_{2} \mathrm{O}_{3}(\mathrm{Fe} 10 \%$ by weight) catalyst and some modifications [68-70]. The latter were obtained by impregnating the same precursor, an iron ferric oxide on alumina, with a suitable salt of a chemical element, then reducing this solid by hydrogen. The four catalysts studied by NGR were reduced inside the Mössbauer cell, then the temperature was decreased to $520 \mathrm{~K}$, at which point $\mathrm{CO}$ was added. From this time several spectra were taken, each one lasting about one hour, throughout catalytic equilibration which was achieved after twenty hours. Each spectrum was fitted and resolved into its components, generally several sextets and doublets, which were attributed to iron species according to their parameters and literature data. From their areas

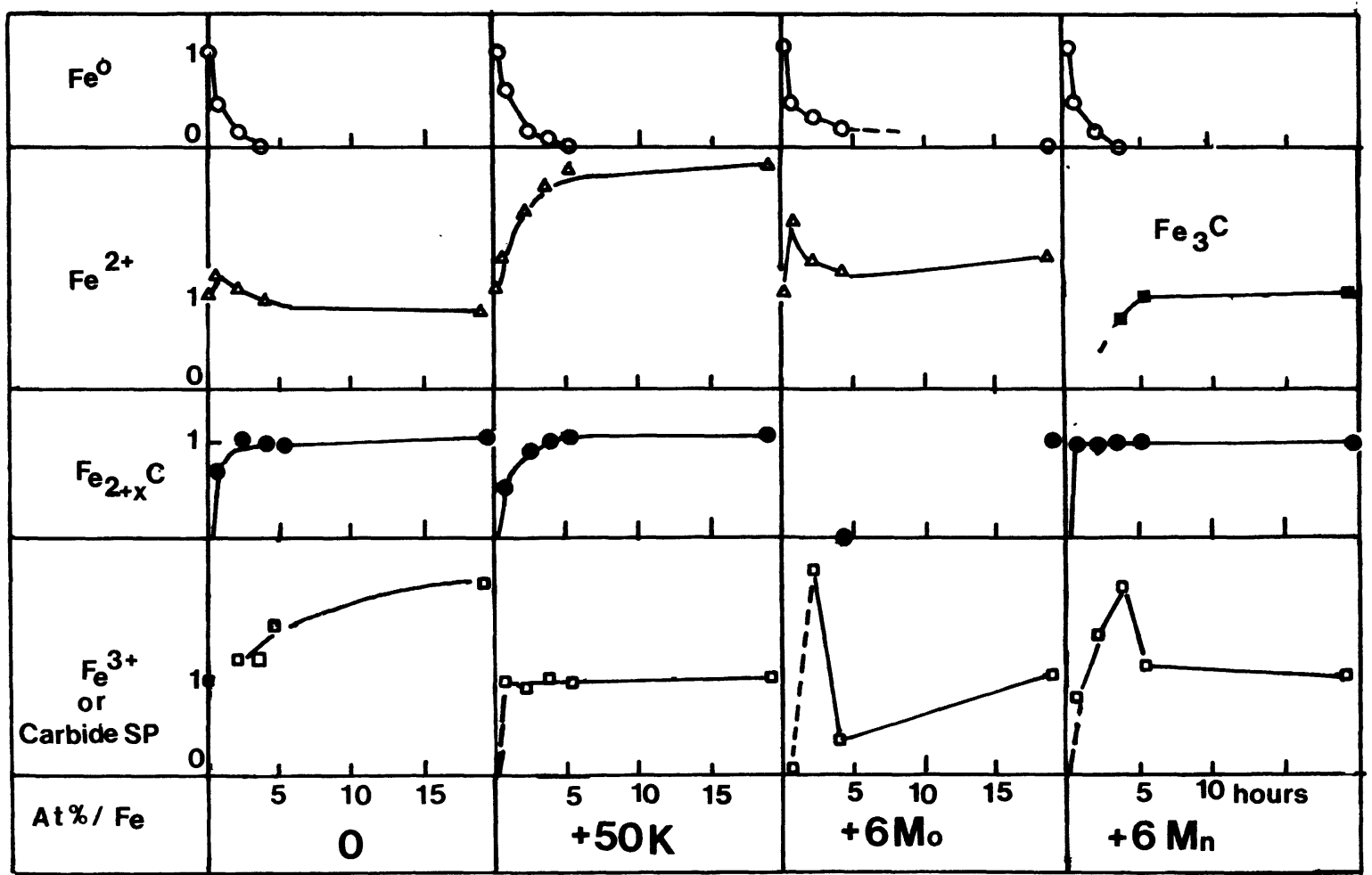

Fig. 7. - Evolution with time of iron species in several catalysts for Fischer-Tropsch synthesis, at $523 \mathrm{~K}$ in the mixture $1 \mathrm{CO}-1 \mathrm{H}_{2}$ at atmospheric pressure. 
and line widths numbers proportional to the product $n f$ (numbers of iron atoms, $n$, Lamb-Mössbauer factors, $f$ ) were calculated. As all $f$ values are not known an absolute determination of $n$ was not possible, but for each component of a catalyst the relative variation of $n$ throughout an experiment could be obtained precisely and is shown in figure 7 . In fact, this procedure requires that $f$ does not vary significantly, which we must discuss briefly in connection with paragraph 2.4 . When a component of the catalyst decreases into a small amount or begins to appear, it can be thought to form fine particles whose the recoilless fraction can take very low values if such particles are loosely bound to their neighbours. Here carbide grows inside a rather large iron particle $(\bar{d} \simeq 40 \mathrm{~nm})$, so its first ordered domains cannot be considered as fine particles with a small number of small areas of contact with a support. A similar situation occurs for the last organized domains of iron metal when approaching total carburization. Indeed the recoilless fractions of such ultimate phases may differ a little from those of bulk species because of differences in vibration frequency distributions, but this effect may only result in a small distortion of the low ordinates parts of the curves in figure 7.

Given the foregoing statements, some conclusions can be drawn from an examination of the curves of figure 7. (I) In all cases, only pure $\alpha-\mathrm{Fe}$ results from reduction by hydrogen (no change in IS and $H$ ), with various degrees of reduction (up to nearly $100 \%$ in the case of manganese addition). Therefore, the differences in selectivities that the additives introduce may be ascribed either to some modified surface atoms (very small percentage of their total number) or to a change in the properties of the support. Indeed the chemical state of these additives should be determined. (II) At catalytic equilibrium, metallic, iron, either ferromagnetic or superparamagnetic, is no longer detectable at the level of less than one percent of the initial amount, which could still correspond to a large fraction of the surface atoms. (III) All iron progressively transforms predominantly into carbides, reaching mainly the state of $\varepsilon-\mathrm{Fe}_{2+x} \mathrm{C}$ characterized by hyperfine fields of about 135 and $205 \mathrm{kOe}$ at $520 \mathrm{~K}$. This assignment is opposite to that given in studies of other catalysts [43, 44, 71, 72], with reference to a description of $\varepsilon-\mathrm{Fe}_{2} \mathrm{C}$ with three hyperfine fields [73], contrary to a more complete understanding of the structure [74]. Carburization does not proceed at a same rate for the four catalysts presented here and even cementite appears in $\mathrm{Fe}(\mathrm{Mn}) / \mathrm{Al}_{2} \mathrm{O}_{3}$. (IV) The spectra contain a paramagnetic component, 5 to $15 \%$ of spectrum area, refered to as $4 \mathrm{Fe}^{3+}$ or superparamagnetic carbide $»$ in figure 7 because the determination of its parameters is not unequivoqual. In the case of $\mathrm{Fe} / \mathrm{Al}_{2} \mathrm{O}_{3}$ this component of the spectra increases throughout the experiment and subsequent NGR at $4 \mathrm{~K}$ revealed a sextet of ferric oxide without a modification of the carbide pattern. However it is not very clear whether the $\mathrm{Fe}^{2+}$ component suffered a partial oxidation or not during exposition to air. $\mathrm{Fe}(\mathrm{K}) / \mathrm{Al}_{2} \mathrm{O}_{3}$ exhibits a growth of the $\mathrm{Fe}^{2+}$ content implying the occurrence of oxidation. (V) Finally carburization and oxidation support the statement that $\mathrm{CO}$ dissociative adsorption is a step in FischerTropsch synthesis, carbon and oxygen reacting separately with iron. Oxides, where they are present, could grow as a consequence of the redox equilibrium appeared in adsorption-desorption experiments (see 4.2). (VI) In $\mathrm{Fe}(\mathrm{Mo}) / \mathrm{Al}_{2} \mathrm{O}_{3}$ carburization is so slow that no ferromagnetic carbide appears during the first hours. Since the formation of hydrocarbons is detected as soon as the reaction is started, it is to be thought that bulk carbide is not an intermediate in the reaction mechanism.

In this study Mössbauer spectroscopy introduced a better understanding of iron based catalysts supported on alumina under reaction conditions. Also, it gave the first answers to questions about the mechanism of Fischer-Tropsch synthesis and posed new ones as well. Similar investigations on catalysts supported on silica [43, 44, 46, 71] and non supported catalysts [72] enable one to begin a comparison which could enlighten the role of supports and the methods of preparation of such solids.

6. Conclusions. - Throughout this critical review of the potential of Mössbauer spectroscopy relative to research in heterogeneous catalysis, we tried only to discuss some examples typical of the various methodologies, catalysts, reactants and fundamental problems in chemisorption and catalysis. As expected, NGR seldom answers questions only by itself but succeeds in this by adding to other physical methods of solid catalysts study, which we could not detail in reporting so briefly on rather extended investigations. However, we can see that it is very powerful and often even necessary in obtaining results quite decisive for a good understanding of catalytic processes. Moreover, there are many results provided by Mössbauer spectroscopy that we have not reported for each example given in the text.

Dealing mainly with small particles these applications are dependent on the knowledge of Mössbauer spectroscopy of fine powders and solid surfaces, and in turn the NGR investigations on catalysts have afforded a significant contribution to this field (section 2). However questions remain, chiefly about isomer shift, to which several factors contribute so that unambiguous experiments and theoretical investigations are needed. A somewhat similar situation exists for magnetic properties but is beginning to clear up.

Particularly because of these peculiarities and also of the complexity of catalytic solids, the problem of catalysts structure is rarely solved from only one spectrum, even though this may contain much information. Obtaining reliable results usually requires 
spectroscopic studies under variable conditions : temperature, time, reactants, and also adsorptiondesorption or oxidation-reduction cycles. This is clear in most examples of sections 3,4 and 5.

The determination of the composition, structure, and nature of the possible active sites of catalysts before use, where Mössbauer spectroscopy provides many meaningful results (section 3), often gives interesting indications about the origin of catalytic activity. Nevertheless statements derived from such investigations often should to be checked by means of in situ studies. The most recent advances in NGR adsorption studies (section 4) introduced interesting approaches to fundamental problems about the chemisorptive bond. This entails working with small particles and dealing with the related difficulties we pointed out above. Such an effort is fully justified by the importance of questions to be answered. In spite of a quick development, Mössbauer spectroscopy in the conditions of catalytic reactions (section 5) must be considered as an only starting research field. Much work is still necessary, and in fact going on in several laboratories, even on catalytic systems already investigated by this manner, because the first studies answered some questions but introduced new ones. Indeed, the best information could result from studying finely dispersed catalysts, although small iron particles, for instance, undergo sintering during catalysis unless their size is limited by surroundings such as inside narrow pores or cavities of a suitable support.

Since iron and tin NGR have had great success in catalysis research as we saw in this review, it appears quite desirable to develop the use of other Mössbauer elements. This requires a special effort in cell technology ensuring quenching from reduction, reaction, or adsorption-desorption conditions to the low temperature necessary for this spectroscopy. At least in the case of transitions of not too high energy, the isotopic sources could be replaced by synchrotron radiation.

The evaluation of seventeen years of NGR applied to heterogeneous catalysis research leads to the conclusion that this method is and will remain very fruitful for a long time, especially when more and more chemists and physicists collaborate in the field, as required by the complexity of both catalysis and Mössbauer spectroscopy.

\section{References}

[1] Martin, G. A., Revue Phys. Appl. 16 (1981) 181.

[2] MathiEU, M. V., id., to be published.

[3] VeDRINe, J., id. 16 (1981) 373.

[4] Dormann, J. L., id. 16 (1981) 275.

[5] Stevens, J. G., Stevens, V. E. and Getrys, W. L., Catalysts Mössbauer Handbook, Mössbauer Effect Data Center, University of North-Carolina, Asheville (1980).

[6] Gol'Danski, V. I., Maksimov, Yu. V. and Suzdalev, I. P., Proceedings of the International Conference on Mössbauer Spectroscopy, Cracow vol. 2 (1975) p. 163.

[7] Dumesic, J. A., J. Physique Colloq. 37 (1976) C6-233.

[8] Dumesic, J. A. and Tops $\phi$ E, H., Adv. Catal. 26 (1976) 121.

[9] TOPsфE, H., Dumesic, J. A. and M $\phi$ RUP, S., in Applications of Mössbauer Spectroscopy, edited by Cohen, R. L. (Academic Press, New York and London) 1980.

[10] Berry, F. J., Adv. Inorg. Chem. Radiochem. 21 (1978) 225.

[11] Bartholomew, C. H. and Boudart, M., J. Catal. 29 (1973) 278.

[12] Сyrot-Lackmann, F., in Growth and properties of metal clusters (Elsevier) 1980, p. 241.

[13] Messmer, R. P., 2nd International Meeting on the small particles and inorganic clusters, Lausanne (1980), to be published in Surf. Sci.

[14] Bussiere, P., Revue Phys. Appl. 15 (1980) 1143.

[15] Viegers, M. P. A. and Trooster, J. M., J. Physique Colloq. 37 (1976) C6-293.

[16] Mфrup, S., Clausen, B. S. and Tops $\phi$ E, H., Surf. Sci. 106 (1981) 438.

[17] Boudart, M., Delbouille, A., Dumesic, J. A., KhamMOUNA, S. and Tops $\phi$ E, H., J. Catal. 37 (1975) 486.

[18] Clausen, B. S., Laboratory for Technical Physics II, Report $n^{\circ} 1$ (1979).

[19] Fujimoto, K. and Boudart, M., J. Physique Colloq. 40 (1979) C2-81.

[20] Hugues, F., Bussiere, P., Basset, J. M., Commereuc, D., Chauvin, Y., Bonneviot, L. and Olivier, D., 7th International Congress on Catalysis, Tokyo (1980), Communication A28.
[21] Philuips, J., Clausen, B. and Dumesic, J. A., J. Phys. Chem. 84 (1980) 1814.

[22] Garten, R. L., in Mössbauer Effect Methodology (Plenum Press, New York and London) vol. 10, 1976, p. 69.

[23] Owens, A. H., Chien, C. L. and Walker, J. C., J. Physique Colloq. 40 (1979) C2-74.

[24] SChmmt, F., GUNSSER, W. and AdolPh, J., in Molecular sieves-II (The American Chemical Society, Washington) 1977, p. 291.

[25] De WAARD, H., in Site characterization and aggregation of implanted atoms in materials, NATO ASI Series B Physics 47 (1980) 413.

[26] Bacaud, R., Bussiere, P. and Figueras, F., J. Catal. to be published.

[27] Shinjo, T., J. Physique Colloq. 40 (1979) C2-63.

[28] Derouane, E. G., Simoens, A., Colin, C., Martin, G. A., Dalmon, J. A. and Vedrine, J. C., J. Catal. 52 (1978) 50.

[29] Freeman, A. J., Wang, C. S., Krakauer, H. and PosterNAK, M., J. Physique Colloq. 41 (1980) C1-39.

[30] Low, M. J. D., in The Solid-gas interface, edited by E. A. Flood, (Dekker) vol. 2, 1967, p. 947

[31] Gol'Danskil, V. I. and Suzdalev, I. P., Usp. Khim. 39 (1970) 1307.

[32] Clausen III, C. A. and Good, M. L., J. Catal. 38 (1975) 92; id., in Mössbauer Effect Methodology (Plenum Press, New York and London) vol. 10 1976, p. 93.

[33] Übelhack, H. J. and WrrtmanN, F. H., J. Physique Colloq. 37 (1976) C6-273.

[34] Hayashi, M., Tamura, I., Fukano, Y. and Kanemaki, S., Surf. Sci. 106 (1981) 453.

[35] Clausen, B. S., M $\phi$ Rup, S., Nielsen, P., Thrane, N. and TOPS $\phi E$, H., J. Phys. E 12 (1979) 439.

[36] Bacaud, R., Bussiere, P. and Figueras, F., J. Physique Colloq. 40 (1979) C2-94; id., J. Catal., to be published.

[37] F. P. 2042984 (1969) to Compagnie Française de Raffinage.

[38] Gray, P. R. and FAHRA, F. E., in Mössbauer Effect Methodology (Plenum Press, New York and London) vol. 10, 1976 p. 47. 
[39] Berndt, H., Mehner, H., Volter, J. and Meisel, W., Z. Anorg. Allg. Chemie 429 (1977) 47.

[40] Garten, R. L., in Mössbauer Effect Methodology (Plenum Press, New York and London) vol. 10, 1976, p. 69.

[41] Vannice, M. A. and Garten, R. L., J. Mol. Catal. 1 (1975/76) 201.

[42] Garten, R. L. and Ollis, D. F., J. Catal. 35 (1974) 232.

[43] Raupp, G. F. and Delgass, W. N., J. Catal. 58 (1979) 337, 348 and 361 .

[44] Unmuth, E. E., Schwartz, L. H. and Butt, J. B., J. Catal. 61 (1980) 242 and 404.

[45] Vannice, M. A., Lam, Y. L. and Garten, R. L., in Hydrocarbon Synthesis from $\mathrm{CO}$ and $\mathrm{H}_{2}$, edited by Kugler, E. L. and Steffgen, F. W. (the American Chemical Society, Washington) 1979, p. 25.

[46] Guczi, L., Schay, Z. and Lázár, K., Surf. Sci. 106 (1981) 516.

[47] Garten, R. L. and Sinfelt, J. H., J. Catal. 62 (1980) 127.

[48] SERIEYs, $M$. and Bussiere, $P$., unpublished results.

[49] Gibson, M. A. and Hightower, J. W., J. Catal. 41 (1976) 431.

[50] Portefaix, J. L., Bussiere, P., Figueras, F., Forissier, M., Friedt, J. M., Theobald, F. and SANChez, J. P., J. Chem. Soc. Farad. Trans. I 76 (1980) 1652.

[51] Berry, F. J., Holbourn, P. E., and Woodhams, W. D., J. Chem. Soc. Dalton Trans. (1980) p. 2241.

[52] Delgass, W. N., Garten, R. L. and Boudart, M., J. Phys. Chem. 73 (1969) 2970.

[53] Dickson, B. L. and Regs, L. V. C., J. Chem. Soc. Far. Trans. I 70 (1974) 2038

[54] Id., ibid., 2051.

[55] Wickman, H. H., in Mössbauer Effect Methodology (Plenum Press, New York and London) vol. 2, 1966, p. 39.

[56] Bussiere, P., Dutartre, R., Martin, C. A. and Mathieu, J. P., C. R. Hebd. Séan. Acad. Sci. Ser. C 280 (1975) 1133 ;

Dutartre, R., Bussiere, P., Dalmon, J. A. and Martin, G. A., J. Catal. 59 (1979) 382.

[57] Nahon, N., Perrichon, V., Turlez, P. and Bussiere, P., React. Kin. Catal. Lett. 11 (1979) 281.

[58] Dutartre, R., Primet, M. and Martin, G. A., React. Kin. Catal. Lett. 3 (1975) 249.

[59] Mфrup, S., Clausen, B. S. and Topsфe, H., J. Physique Colloq. 41 (1980) C1-331.

[60] Id., J. Physique Colloq. 40 (1979) C2-78.

[61] Herpin, A., Théorie du Magnéttsme (P.U.F., Paris) 1968.
[62] Dumesic, J. A., Maksimov, Yu. V. and Suzdalev, I. P., in Mössbauer Effect Methodology (Plenum Press, New York and London) vol. 10, 1976, p. 31.

[63] Dumesic, J. A., Topsфe, H. and Boudart, M., J. Catal. 37 (1975) 513

[64] Maksimov, Yu. V., Suzdalev, I. P., GoldanskiI, V. I., Krylov, O. V., Margolis, L. Ya and Nechitailo, A. E., Chem. Phys. Lett. 34 (1975) N1, 172.

[65] Topsoe, H., Clausen, B. S., Burriesci, N., Candia, R. and M $\phi$ RUP, S., in Preparation of Catalysis II (Elsevier, Amsterdam) 1979, p. 479.

[66] Clausen, B. S., Ph. D. Dissertation, Technical University of Denmark, Copenhague, 1979.

[67] Breysse, M., Bennett, B. A. and Chadwick, D., to be published.

[68] Nahon, N., Perrichon, V. and Turlier, P., React. Kinet. Catal. Lett. 12 (1979) 139.

[69] Nahon, N., Perrichon, V., Turlier, P. and Bussiere, P., J. Physique Colloq. 41 (1980) C1-339; id., in Magnetic Resonance in Colloid and Interface Science, edited by J. P. Fraissard and H. A. Resing (Reidel Publishing Company, Dordrecht N.L.) 1980, p. 377.

[70] Puolat, M. et al., to be published.

[71] Amelse, J. A., Butt, J. B. and Schwartz, L. H., J. Phys. Chem. $82(1978) 558$

[72] Niemantsverdriet, J. W., Van Der Kraan, A. M., Van Dujx, W. L. and Van Der BaAN, H. S., J. Phys. Chem. 84 (1980) 3363.

[73] Arents, R. A., Maksimov, Yu. V., Suzdalev, I. P., ImshenNIK, V. K. and KruPYanskn, Yu. F., Fiz. Metal. Metalloved. 36 (1973) 277.

[74] Dubors, J. M. and Le Cá́r, G., Acta Metall. 25 (1977) 609.

[75] Lyon, Institut de Recherches sur la Catalyse du CNRS, F 69626 Villeurbanne. Liste des conférences présentées (sujet : Surfaces, grains fins, catalyse) :

COEY, J. M. D., At. Energ. Rev. 18(1980) 73

Scheshter, H., SuzanNe, J., Dash, J. G., J. Physique 40 (1979) 467

Dormann, J. L., Revue Phys. Appl. 16 (1981) 275.

MATHIEU, M. V., id. (sous presse).

VeDRINe, J., id. 16 (1981) 373.

Martin, G. A., id. 16 (1981) 181.

BUSSIERE, P., présent article. 